\title{
A rare missense variant in RET exon 8 in a Portuguese family with atypical multiple endocrine neoplasia type $2 \mathrm{~A}$
}

\author{
Ana Filipa Martins, ${ }^{1}$ João Martin Martins, ${ }^{1,2}$ Sónia do Vale, ${ }^{1,2}$ Teresa Dias, ${ }^{1}$ \\ Catarina Silveira, ${ }^{3}$ Inês Rodrigues da Silva, ${ }^{3}$ Maria Carmo-Fonseca ${ }^{2,3}$
}

${ }^{1}$ Serviço de Endocrinologia, Hospital de Santa Maria; ${ }^{2}$ Faculdade de Medicina, Universidade de Lisboa; ${ }^{3}$ Genomed, Instituto de Medicina Molecular, Centro Académico de Medicina de Lisboa; Lisboa, Portugal

\begin{abstract}
BACKGROUND AND OBJECTIVE: Multiple Endocrine Neoplasia type 2 (MEN2) is a rare genetic disorder characterized by medullary thyroid carcinoma (MTC), pheochromocytoma and primary hyperparathyroidism. MEN2 is an autosomal dominant syndrome caused by mutations in the $R E T$ proto-oncogene. In the vast majority of patients, the mutations are localized in exons 10, 11 and 13-15 of the $R E T$ gene. Rare variants located in exon 8 were recently identified but their clinical significance remains unclear. DESIGN AND METHODS: We studied two sisters presenting with pheochromocytoma as the first tumor. One of the sisters was diagnosed with a right pheochromocytoma at the age of 44 and at age 53 she developed an invasive left pheochromocytoma with no other endocrine neoplasia. The other sister was diagnosed with a left pheochromocytoma at age 50 and at age 64 she had a right phemochromocytoma and MTC. Neither of the two sisters presented evidence of primary hyperparathyroidism. Mutations of the RET proto-oncogene were investigated by DNA sequencing. RESULTS: We detected a germline missense variant in $R E T$ exon 8 (p.Cys531Arg) in both sisters. The p.Cys531Arg variant was not present in a third 50-year-old sister who has remained to date clinically unaffected. CONCLUSION: This is the first case showing the p.Cys531Arg variant in RET exon 8 co-segregating with family members affected by a syndrome reminiscent of MEN2A. Our results suggest that this variant has a specific genotype-phenotype correlation as it is associated with the development of pheochromocytoma before the onset of MTC.
\end{abstract}

Key words: MEN2A, Pheochromocytoma, RET mutation

\section{INTRODUCTION}

Multiple Endocrine Neoplasia type 2 (MEN2,

Address for correspondence:

Ana Filipa Martins, MD, BEE, Endocrine Department, Hospital de Santa Maria, $6^{\text {th }}$ floor, Av. Prof. Egas Moniz, 1649-028 Lisboa, Portugal; Mobile: +351968932314, E-mail: anafgmartins@gmail.com

Received: 16-02-2016, Accepted: 31-05-2016
OMIM 171400) is a rare (approximately one in 200,000 live births) autosomal dominant tumor syndrome. Distinct MEN2 subtypes have been recognized. ${ }^{1-5}$ MEN2A is the most common form of MEN2 and its first manifestation is often MTC, usually occurring between the ages of 20 and 30 years. ${ }^{6}$ MEN2A is characterized by MTC and pheochromocytoma plus primary hyperparathyroidism. ${ }^{7}$ 
Since the discovery of the MEN2 causative gene, the RET proto-oncogene, direct genetic testing for at-risk individuals has been recommended. ${ }^{8}$ Patients with germline RET mutations may undergo risk assessment and may be offered thyroidectomy prior to developing clinically evident MTC. ${ }^{9,10}$ However, due to the varying clinical effects of RET mutations, establishing precise genotype-phenotype correlations remains challenging. The RET gene is located on chromosome 10 (10q11.2) and comprises 21 exons that encode for a transmembrane tyrosine kinase receptor involved in growth and differentiation of neural crest-derived tissues. ${ }^{7,11,12}$ Most RET mutations are located in one of six conserved cysteines in the extracellular domain that induce a ligand-independent RET domerization. ${ }^{13-16}$ Although most characterized RET mutations are located in exons $10,11,13,14$, 15 and $16,{ }^{17,18}$ additional mutations in exons 5 and 8 have been reported. ${ }^{19}$

Here we report a rare germline missense variant in RET exon 8 (p.Cys531Arg) that co-segregates with affected siblings in an atypical Portuguese MEN2A family. The p.Cys531Arg variant was recently identified in apparently sporadic cases of MTC, ${ }^{19}$ but its clinical significance remains unclear. Our results show that this variant is associated with the development of pheochromocytoma before the onset of MTC, thus suggesting a novel genotype-phenotype correlation.

\section{CASE REPORT}

A 44-year-old Caucasian female (index case) was admitted to our endocrine outpatient department in 1995 because of paroxysmal hypertension and headaches lasting for several weeks. As biochemical and functional evaluation was indicative of leftsided pheochromocytoma, she was submitted to left adrenalectomy. There was no evidence of any other endocrine neoplasia. At age 53 a right pheochromocytoma was confirmed on ${ }^{123}$ I-MIBG scanning. Right adrenalectomy was performed. Two years later liver and paravertebral metastasis were found and treated with ${ }^{131}$ I-MIBG (total activity $800 \mathrm{mCi}$ ). At age 57 a slight calcitonin elevation was first detected $[6 \mathrm{pg} / \mathrm{mL}$ (Reference Value $<5 \mathrm{pg} / \mathrm{mL}$ )], as well as a $17 \times 14 \mathrm{~mm}$ hypoechogenic thyroid nodule that was found to be benign after histological analysis. When she was 63 (in 2013), hyperparathyroidism with hypercalcemia lacking surgical criteria were detected (Table 1). Both parathyroid function and calcitonin are under careful follow-up. The authors do not exclude the possibility that the moderate increase in calcitonin is related either to the hyperparathyroidism or to the malignant pheochromocytoma, as this hormone is also produced in chromaffin cells. ${ }^{20}$ Indeed, both sporadic and familial pheochromocytomas have previously been associated with calcitonin production. ${ }^{21,22}$ At the same time, normetanephrines were still high and did not suppress on the clonidine test (Table 2). ${ }^{123}$ I-MIBG scanning revealed high uptake in lesions diagnosed in the mediastinum and left pulmonary apex, as well as in the lower right paramedian mediastin and left dorsal paramedian region. A new therapeutic session with ${ }^{131}$ I-MIBG was offered.

The 50-year-old female sister of the index case presented in 1993 with clinical, analytical and imagiologic evidence of a left pheochromocytoma with no evidence of any other endocrine neoplasia. Left adrenalectomy was performed. Two years later, in 1995, when her sister was first diagnosed with pheochromocytoma, both sisters were submitted to genetic testing for the most common RET and SHD mutations but none were

Table 1. Analytic evaluation of Case 1 in 2013, when she was 63 years old. Mild hyyperparathyroidism with hypercalcemia, as well as mild calcitonin elevation were diagnosed

\begin{tabular}{lc}
\hline Parameter (Reference Value) & Value \\
\hline PTH $(14-72 \mathrm{pg} / \mathrm{mL})$ & 128 \\
Vitamin D $(30-80 \mathrm{ng} / \mathrm{mL})$ & 22.2 \\
Serum Calcium $(8.6-10.2 \mathrm{mg} / \mathrm{dL})$ & 10.7 \\
Serum Phosphorus $2.4-5.1 \mathrm{mg} / \mathrm{dL}$ & 3.4 \\
Calcitonin $(<5 \mathrm{pg} / \mathrm{mL})$ & 6.4 \\
NSE $(0-16.3 \mathrm{ug} / \mathrm{L})$ & 20 \\
\hline
\end{tabular}

Table 2. Clonidine Suppression Test performed in Case 1 after bilateral adrenalectomy: normetanephrine values were initially high and did not suppress after clonidine administration

\begin{tabular}{lcc}
\hline \multicolumn{3}{l}{ Clonidine Suppression Test (300mg po) } \\
\hline 0 min & $\mathbf{1 8 0 ~}$ min \\
\hline Metanephrines $(<90 \mathrm{ug} / 24 \mathrm{~h})$ & 85 & 50 \\
Normetanephines $(<180 \mathrm{ug} / 24 \mathrm{~h})$ & 464 & 231 \\
\hline
\end{tabular}


detected. At age 64 a right phemochromocytoma was found and surgically resected. At age 65 the patient presented increased serum calcitonin levels and was diagnosed with MTC following total thyroidectomy.

In 2013, genomic DNA was extracted from both patients and their unaffected sister. For the index case, exons 5, 8, 10,11 13,14, 15 and 16 of the RET gene (10q11.21, OMIM 164761, NM_020630.4) were analyzed. In addition, 100-200 intronic nucleotides flanking each splice site were sequenced. The nomenclature used to describe the genetic variants follows the Human Genome Variation Society (HGVS) guidelines. Two heterozygous variants were identified (Figure 1). One is located in exon 8 and

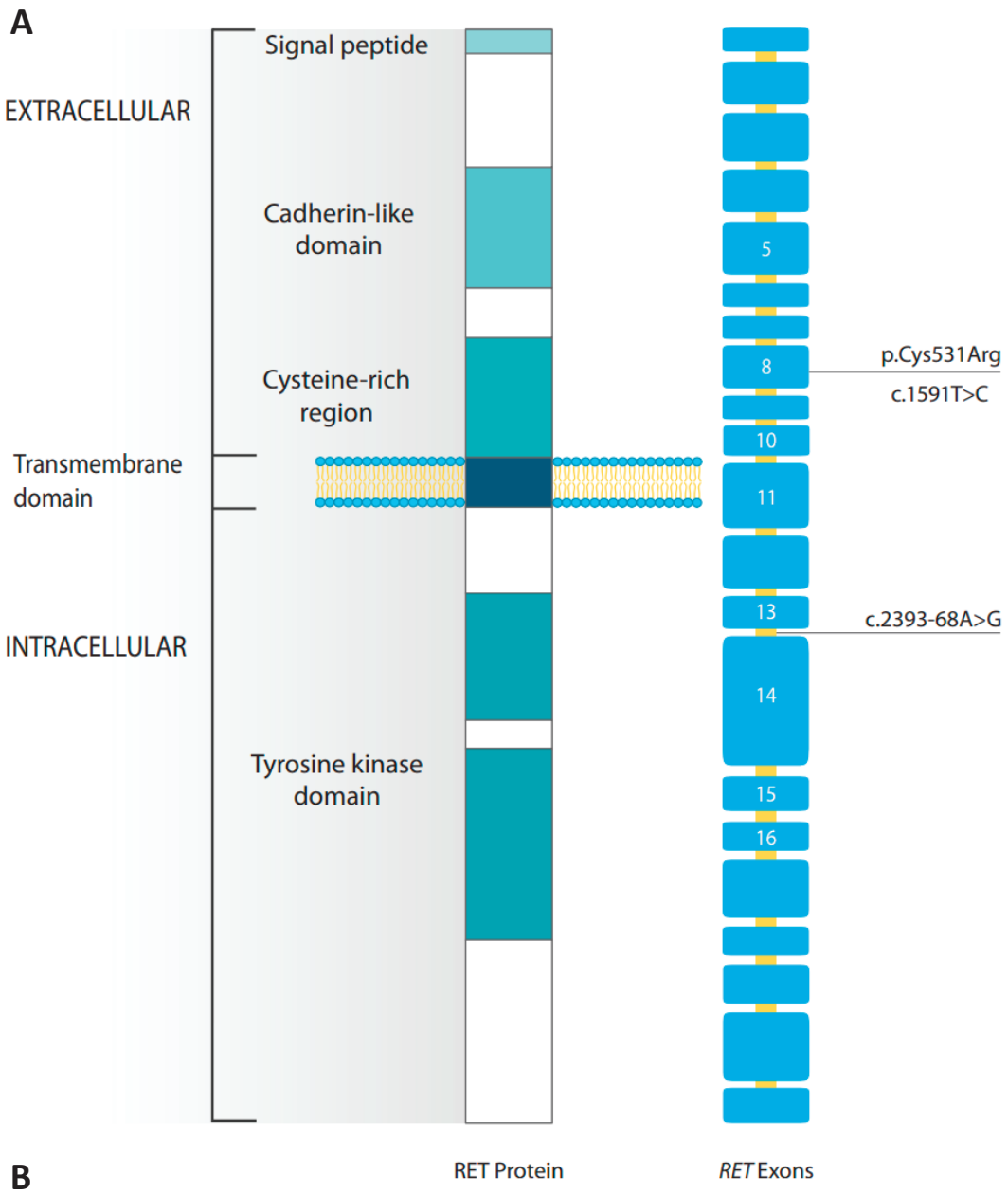

\section{Exon 8}

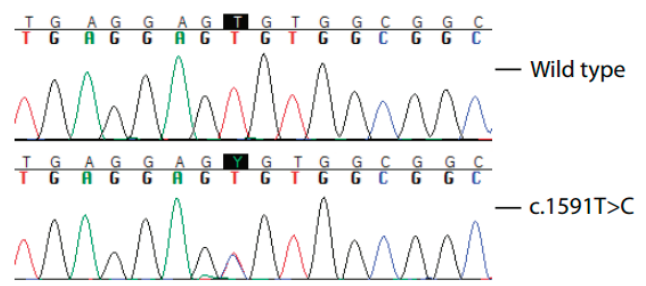

Intron 13

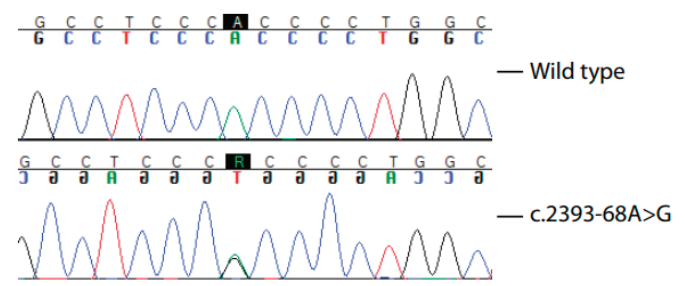

Figure 1. A) Schematic illustration of RET protein domains and exonic structure of RET mRNA. The locations of the variants are indicated. B) Identification of variants by sequence analysis of the RET gene. 
consists of a $\mathrm{T}$ to $\mathrm{C}$ substitution at position c.1591, leading to a cysteine to arginine amino acid change in codon 531 (c.1591T $>$ C, p.Cys531Arg). The second variant is located in intron 13 and consists of $A$ to $G$ substitution at position c.2393-68 (c.2393-68A > G). In light of these results, we next screened RET exons 8 and 14 in the two sisters. The affected sister was also heterozygous for both variants. The asymptomatic sister carried the intron 13 variant but the sequence of exon 8 is normal. The parents of the three sisters were unavailable for DNA testing. The offspring of the two affected sisters were not genetically analyzed; they are clinically and biochemically asymptomatic.

\section{DISCUSSION}

Most MEN2 families studied so far have germlineactivating mutations of the RET proto-oncogene in exons 10, 11 and 13-15. Although genetic variants in other locations along the gene have been identified, their clinical significance remains unclear. ${ }^{19,23-31}$ In this report we describe a family with a syndrome reminiscent of MEN2A that carries two distinct RET variants. The c.2393-68A $>\mathrm{G}$ intronic variant has been previously described ${ }^{32}$ and is included in the NCBI database of single nucleotide polymorphisms (http://www.ncbi.nlm.nih.gov/projects/SNP/sn_pref. cgi?rs=57622093 6). An in silico analysis performed with MutationTaster (www.mutationtaster.org) indicates that this variant does not affect splicing. Consistent with the view that this variant is likely benign, it is present in the asymptomatic 50-year-old sibling of the two patients. In contrast, the c. $1591 \mathrm{~T}>\mathrm{C}$ variant in exon 8 is present in the two affected sisters but not in the asymptomatic sibling.

The c. $1591 \mathrm{~T}>\mathrm{C}$ variant is a missense genomic alteration in codon 531 causing substitution of a cysteine by an arginine in the extracellular cysteinerich domain of the RET receptor. Although it is still described in the ARUP ${ }^{\circledR}$ MEN2 database (http://www. arup.utah.edu/database/MEN2/MEN2_welcome.php) as a variant of unknown functional significance, in silico analysis performed with MutPred (http:// mutpred.mutdb.org/), PolyPhen (http://genetics.bwh. harvard.edu/pph2/) and UMD (http://umd-predictor. eu) indicates that this variant is probably damaging.
When HEK 293T cells were transiently transfected with an expression vector for the C531R variant, the mutant protein was more tyrosine phosphorylated than wild-type RET, suggesting that receptors with this mutation can be activated even in the absence of the ligand. ${ }^{19,33}$ However, the amount of phosphorylation found for p.C531R was significantly lower than that obtained with the most common MEN2A-causing mutation p.C634R. ${ }^{9}$ Moreover, in contrast to cysteines encoded in exons 10 and 11, which are commonly mutated in hereditary MEN2, cysteine 531 is less conserved throughout evolution. ${ }^{34}$ Taken together, these observations suggest that mutation of cysteine 531 can activate the RET receptor but has mild oncogenic potential. In agreement with this interpretation, the two patients studied developed tumours much later than typical MEN2A cases.

The two sibling patients reported in this study presented additional features that are unusual in typical MEN2A cases. First, the index case had malignant pheochromocytoma, which is very rare in MEN2A. ${ }^{35}$ Second, pheochromocytoma was the only neoplasia identified in the index case and in her affected sister pheochromocytoma preceded MTC. This raises the hypothesis that the p.C531R mutation is associated with higher incidence of pheochromocytoma. In agreement with this view, patients with another mutation in exon 8 (G533C) had pheochromocytoma preceding MTC, ${ }^{28,29}$ while an American family with 47 affected relatives also showed a strong association of this mutation with pheochromocytoma. ${ }^{31}$

In conclusion, we report a family carrying a rare germline missense variant in RET exon 8 that is associated with late-onset pheochromocytoma before development of MTC. Given that direct genetic testing is crucial for accurate diagnosis of MEN2, molecular risk assessment, informed family counseling and therapeutic profiling, our report provides new insight into genotype-phenotype associations involving mutations in RET exon 8.

\section{DECLARATION OF INTEREST}

There is no conflict of interest that could be perceived as prejudicing the impartiality of the research reported. 


\section{FUNDING}

This research did not receive any specific grant from any funding agency in the public, commercial or not-for-profit sector.

\section{REFERENCES}

1. Krampitz GW, Norton JA, 2014 RET gene mutations (genotype and phenotype) of multiple endocrine neoplasia type 2 and familial medullary thyroid carcinoma Cancer 120: 1920-1931.

2. Hoff AO, Cote GJ, Gagel RF, 2000 Multiple Endocrine Neoplasias. Ann Rev Physiol 62: 377-411.

3. Pellegata N, 2012 MENX and MEN4. Clinics 67: Supp 1: 13-18.

4. Georgitsi M, Raitila A, Karhu A, 2007 Germline CDKN1B/p27Kip1 Mutation in Multiple Endocrine Neoplasia. J Clin Endocrinol Metab 92: 3321-3325.

5. Weinstein L, 2007 Gs Mutations in Fibrous Dysplasia and McCune-Albright Syndrome. J Bone Miner Res 21: $120-124$.

6. Raue F, Frank-Raue K, 2009 Genotype-phenotype relationship in multiple endocrine neoplasia type 2 . Implications for clinical management. Hormones (Athens) 8: 23-28.

7. Romei C, Pardi E, Cetani F, Elisei R, 2012 Genetic and Clinical Features of Multiple Endocrine Neoplasia Type 1 and 2 - Review Article. J Oncol 2012: 705036.

8. Hansford JR, Mulligan LM, 2000 Multiple endocrine neoplasia type 2 and RET: from neoplasia to neurogenesis. J Med Genet 37: 817-827.

9. Machens A, Dralle Henning, 2012 Multiple endocrine neoplasia type 2: achivements and current challenges. Clinics 67: Supp 1: 113-118.

10. Eng C, Clayton D, Schuffenecker I, et al, 1996 The relationship between specific RET Proto-oncogene mutations and disease phenotype in Multile Endocrine Neoplasia Type 2. JAMA 276: 1575-1579.

11. Pachnis V, Mankoo B, Costantini F, 1993 Expression of the c-ret proto-oncogene during mouse embryogenesis. Development 119: 1005-1017.

12. Gardner E, Papi L, Easton DF, et al, 1993 Genetic linkage studies map the multiple endocrine neoplasia type 2 loci to a small interval on chromosome 10q11.2. Hum Mol Genet 2: 241-246.

13. Santoro M, Carlomagno F, Romano A, et al, 1995 Activation of RET as a dominant transforming gene by germline mutations of MEN2A and MEN2B. Science 267: 381-383.

14. Takahashi M, Cooper G, 1987 ret Transforming Gene Encodes a Fusion Protein Homologous to Tyrosine Kinases. Mol Cell Biol 7: 1378-1385.

15. Wagner S, Zhu S, Nicolescu A, 2012 Molecular mechanisms of RET receptor-mediated oncogenesis in multiple endocrine neoplasia 2. Clinics 67: Suppl 1: 77-84.

16. Songyang Z, Carraway KL, Eck MJ, et al, 1995 Catalytic specificity of protein-tyrosine kinases is critical for selective signalling. Nature 373: 536-539.

17. Chen H, Sippel RS, O’Dorisio MS, Vinik AI, Lloyd RV, Pacak K; North American Neuroendocrine Tumor Society (NANETS), 2010 The North American Neuroendocrine Tumor Society consensus guideline for the diagnosis and management of neuroendocrine tumors: pheochromocytoma, paraganglioma, and medullary thyroid cancer. Pancreas 39: 775-783.

18. Puñales MK, Graf H, Gross JL, Maia AL, 2003 RET Codon 634 Mutations in Multiple Endocrine Neoplasia Type 2: Variable Clinical Features and Clinical Outcome. J Clin Endocrinol Metab 88: 2644-2649.

19. Muzza M, Cordella D, Bombled J, et al, 2010 Four novel germline variants in exons 8 and 11 display an oncogenic potencial in vitro. Eur J Endoc 162: 771-777.

20. Toledo SP, Lourenço DM Jr, Santos MA, Tavares MR, Toledo RA, Correia-Deur JE, 2009 Hypercalcitoninemia is not pathognomonic of medullary thyroid carcinoma. Clinics 64: 699-706.

21. Komminoth P, Roth J, Schröder S, Saremaslani P, Heitz PU, 1995 Overlaping expression of immunohistochemical markers and synaptophysin mRNA in pheochromocytomas and adrenocortical carcinomas. Implication for the differential diagnosis of the adrenal gland tumors. Lab Invest 72: 424-431.

22. Tessitore A, Sinisi AA, Pasquali D, et al, 1999 A Novel Case of Multiple Endocrine Neoplasia Type 2A Associated with Two de Novo Mutations of the RET Protooncogene. J Clin Endocrinol Metab 84: 3522-3527.

23. Pigny P, Bauters C, Wemeau JL, et al, 1999 A novel 9-base pair duplication in RET exon 8 in familial medullary thyroid carcinoma. J Clin Endocrinol Metab 84: 1700-1704.

24. Niccoli-Sire P, Murat A, Rohmer V, et al, 2003 When should thyroidectomy be performed in familial medullary thyroid carcinoma gene carriers with non-cysteine RET mutations? Surgery 134: 1029-1036.

25. Fazioli F, Piccinini G, Appolloni G, et al, 2008 A new germline point mutation in Ret exon 8 (Cys515Ser) in a family with medullary thyroid carcinoma. Thyroid 18: 775-782.

26. Da Silva AM, Maciel RM, Da Silva MR, Toledo SR, De Carvalho MB, Cerutti JM, 2003 A novel germ-line point mutation in RET exon $8(\mathrm{Gly}(533) \mathrm{Cys})$ in a large kindred with familial medullary thyroid carcinoma. J Clin Endocrinol Metab 88: 5438-5443.

27. Kaldrymides P, Mytakidis N, Anagnostopoulos T, et al, 2006 A rare RET gene exon 8 mutation is found in two Greek kindreds with familial medullary thyroid carcinoma: implications for screening. Clin Endocrinol 64: 561-566.

28. Bethanis S, Koutsodontis G, Palouka T, et al, 2007 A 
newly detected mutation of the RET protooncogene in exon 8 as a cause of multiple endocrine neoplasia type 2A. Hormones (Athens) 6: 152-156.

29. Peppa M, Boutati E, Kamakari S, et al, 2008 Multiple endocrine neoplasia type $2 \mathrm{~A}$ in two families with the familial medullary thyroid carcinoma associated G533C mutation of the RET proto-oncogene. Eur J Endocrinol 159: 767-771.

30. Sarika HL, Papathoma A, Garofalaki M, et al, 2012 High prevalence of exon 8 G533C mutation in apparently sporadic medullary thyroid carcinoma in Greece. Clin Endocr 77: 857-862.

31. Castro MR, Thomas BC, Richards ML, Zhang J, Morris JC, 2013 Multiple Endocrine Neoplasia Type 2A Due to an Exon 8 (G533C) Mutation in a Large North American Kindred. Thyroid 23: 1547-1552.

32. Margraf RL, Durtschi JD, Stephens JE, Perez M, Voelk- erding KV, 2012 Determination of RET Sequence Variation in an MEN2 Unaffected Cohort Using MultipleSample Pooling and Next-Generation Sequencing. J Thyroid Res 2012: 318232.

33. Asai N, Iwashita T, Matsuyama M, Takahashi M, 1995 Mechanism of activation of the ret ptoto-oncogene bu multiple endocrine neoplasia 2A mutations. Mol Cel Biol 15: 1613-1619.

34. Kashuk CS, Stone EA, Grice EA, et al, 2005 Phenotype-genotype correlation in Hirschsprung disease is illuminated by comparative analysis of the RET protein sequence. Proc Natl Acad Sci U S A 102: 8949-8954.

35. Machens A, Lorenz K, Dralle H, 2013 Peak incidence of pheochromocytoma and primary hyperparathyroidism in multiple endocrine neoplasia 2: need for age-adjusted biochemical screening. J Clin Endocrinol Metab 98: E336-345. 